\title{
A Case Study of Biosurfactant Producing Bacterial Bloom from Oil Contaminated Sites After Flood in Kerala
}

\author{
Kizhakkeveettil Abdul Salim Nimsi", Manzur Ali, Muhseena Kallepadath, Mary Romiya Roy, \\ Alna Kochupanikodath Roshna
}

Department of Biosciences, MES College Marampally, Aluva, India

Email address:

nimsishiraz@gmail.com (K. A. S. Nimsi)

${ }^{*}$ Corresponding author

\section{To cite this article:}

Kizhakkeveettil Abdul Salim Nimsi, Manzur Ali, Muhseena Kallepadath, Mary Romiya Roy, Alna Kochupanikodath Roshna. A Case Study of Biosurfactant Producing Bacterial Bloom from Oil Contaminated Sites After Flood in Kerala. American Journal of Modern Energy.

Vol. 5, No. 2, 2019, pp. 35-39. doi: 10.11648/j.ajme.20190502.15

Received: March 11, 2019; Accepted: May 28, 2019; Published: June 18, 2019

\begin{abstract}
Petroleum spillage around the world have played major role in generating the solid Wastes during the tanker accidents and stocking of crude oil. The ecology of hydrocarbon degradation by microbial populations in the natural environment is analysed, highlighting the physical, chemical, and biological factors that cause the biodegradation of petroleum and individual hydrocarbons. Therefore, the present study has shown that the indigenous Bacillus sp., isolated from the polluted study sample (Kochi) possessed the capacity to produce suitable biosurfactant. The effectiveness of the bioremediation mediated by the biosurfactant extract was studied by finding out the germination percentage of a fast growing leguminous plant (Pisum sativum). Therefore the findings of the study revealed that the bacillus sp., isolated from Kochi possesses remarkable oil degrading properties and can be effectively employed in the bioremediation of oil contaminated soils. It can be considered as one the effective clean-up technologies of the future.
\end{abstract}

Keywords: Bioremediation, Biostimulation, Biodegradation

\section{Introduction}

Oil spills have become a global problem particularly in industrialized and developing countries. Attention has been focused on the marine environment, because oceans and estuaries have generally been the sites of largest and most dramatic spills. Apparently inevitable spillages, which occur during routine operations of crude oil production, refining, distribution and as a consequence of acute accidents, have generated continuous research interest in this field [1, 2]. After a large marine spill, petroleum rises to the water surface and begins to spread. Technological advances have increased the effectiveness of chemical dispersants, mechanical containment, and absorption as first-response techniques, but if seas are rough or response time is slow, the spill becomes nearly impossible to contain $[3,4]$. When spills occur near land, oil usually washes up and contaminates near shore and on-shore sediments [5-7]. In these beach sediments, as well as in terrestrial leaks and spills, physical removal of the petroleum is difficult and costly $\{8]$. Removal of hydrocarbon oil by natural process such as photooxidation, evaporation and microbial degradation may take several years. Bio surfactants are amphiphilic molecules with effective surface-active and biological properties applicable to replace synthetic surfactant in several industries and processes $[9,10]$. Bio surfactants are surface-active compound produced by many microorganisms [11-13]. They are amphiphilic molecules produced on microbial cell surfaces that stimulating release of oil entrapped within the capillaries, wetting of solid surfaces, reduction of oil viscosity and oil pour point, lowering of interfacial tension, and dissolution of oil. Bio surfactant is very interesting because their advantage such as biodegradability, low toxicity, ecological acceptability and ability to be produced from renewable and cheaper substrates [14-17]. The objective of this study was to isolate and screening biosurfactant producing bacteria from petroleum oil contaminated terrestrial samples collected in Kerala after flood. $[18,19]$ 


\section{Materials and Methods}

\subsection{Sample Collection}

The five different study sites include Kochi, Alappuzha, Kollam Kannur and Kasaragod. The soil at the sites had a characteristic black color due to continuous soil spillage and the soil surfaces were hard. Samples were collected in each site by digging up the soil with a hoe and transferring directly into clean, sterile containers. Also, clean soil samples were collected from non-contaminated areas for reference.

\subsection{Isolation of Bacterial Oil Degraders}

Bacterial species were isolated from the collected soil samples by serial dilution and agar plating method where in the soil sample was diluted from $10^{-1}$ to $10^{-7}$ dilutions, and diluted soil samples were spread on sterile BHA plates supplemented with used engine oil. The inoculated plates were incubated at $37^{\circ} \mathrm{C}$ for 24 hours. Zone of clearance indicates the growth of bacterial oil degraders. Mixed cultures obtained after incubation were named as isolate 1 (Kochi), isolate 2 (Alappuzha), isolate 3 (Kollam), isolate 4 (Kannur), Isolate 5 (Kasarkode) tentatively and were purified by quadrant streaking on sterile BHA plates.

\subsection{Staining and Biochemical Activities of Purified Cultures}

In order to identify the purified cultures tentatively on the basis of Begay's manual various staining and biochemical tests were performed. Staining includes Gram's staining and Endospore staining. Ten biochemical tests were performed in order to identify the eight unknown bacteria. Some of the tests provided immediate results while others had to incubate for a period of time. Twelve biochemical tests were performed in order to identify the organism. It includes IMVic, citrate utilization, urease, nitrate reduction, sugar fermentation including glucose, lactose, sucrose, and mannose, oxidase, catalase.

\subsection{Antibiotic Sensitivity Test}

For testing the antibiotic sensitivity of the bacterial isolates, the four cultures were swabbed to sterile Muller Hinton Agar. Antibiotic discs were placed on to the plates using a sterile forceps. Incubated at $37^{\circ} \mathrm{C}$ for 24 hours. Zone of clearance around the disc indicates their sensitivity. Measurement of zone diameter and their comparison with the standard chart was performed to identify the sensitivity, susceptibility and resistance

\subsection{Screening of Purified Cultures for the Degradation of Oil}

Oil degradation studies of purified cultures were performed using used engine oil. The components for preparing $100 \mathrm{ml}$ of nutrient broth were dissolved in $75 \mathrm{ml}$ distilled water and $25 \mathrm{ml}$ of used engine oil was added, $\mathrm{pH}$ was maintained to 7 . Media with oil was autoclaved at 15 psi for 20 minutes. Cooled media was inoculated with $1 \mathrm{ml}$ of 24 hour old grown culture of the respective pure cultures. The inoculated tubs were incubated for 7 days.

\subsection{Screening of Biosurfactant Producing Isolates}

The isolates of the microbes thus obtained was then screened for production of oil degrading bio surfactant. In our present study the screening was done by the following methods:

\subsubsection{Drop Collapse Method}

Bio surfactant production was screened using the qualitative drop collapse test. $2 \mu 1$ of diesel was added to 96 well micro-titer plates. The plates were equilibrated for 1 hour at $37^{\circ} \mathrm{C}$ and $5 \mu \mathrm{l}$ of the respective culture supernatant obtained from the different soil samples was added to the surface of the oil in the well. The shape of the drop on the oil surface was observed for 1 minute. If the culture supernatant makes the drop collapse, it indicated positive result for bio surfactant presence and if the drop remained as such it indicated negative result.

\subsubsection{Oil Spread Method}

The petriplate base was filled with $50 \mathrm{ml}$ of distilled water. On the water surface, $20 \mu \mathrm{l}$ of diesel and $10 \mu \mathrm{l}$ of culture were added respectively. The culture was introduced at different spots on the Diesel which is coated on the water surface. The occurrence of a clear zone was an indicator of positive result.

\subsubsection{Emulsification Index (E24)}

The emulsifying capacity was evaluated by an emulsification index. The E24 of the culture samples was determined by adding $2 \mathrm{ml}$ of diesel and $2 \mathrm{ml}$ of the inoculum in a test tube and it was shaken for 2 minutes. Then, water and diesel were added and shaken for 2 minutes to obtain maximum emulsification and allowed to stand for 24 hours. This was taken as control. The percentage of the E24 index is calculated by the following formula:

$$
E 24=\frac{\text { Height of the emulsified layer }(\mathrm{cm}) \times 100}{\text { Total height of the column }(\mathrm{cm})}
$$

\subsubsection{Screening for Oil Degrading Enzyme Activity}

Tributyrin plate assay: Media containing $0.5 \%$ peptone, $0.3 \%$ yeast extract, $1 \%$ Tributyrin and $2 \%$ agar was prepared. The $\mathrm{PH}$ was adjusted to $7.5 \pm 0.2$. The plates were then incubated with the isolates at $37^{\circ} \mathrm{C}$ for 24 hours. The presence of halo was observed and the diameter of the halo was recorded.

\subsubsection{Analysis for Esterase Activity}

Esterase activity was assayed using Tween 80 . The media contained Peptone (10g), Nacl $(5 \mathrm{~g}), \mathrm{CaCl}_{2} .2 \mathrm{H}_{2} \mathrm{O}(0.1 \mathrm{~g})$ and agar $(18 \mathrm{~g})$. The $\mathrm{pH}$ was adjusted to 7.4 . To the sterilized culture media, Tween 80 was added at a concentration of $1 \%$. The medium was incubated with the isolates and the presence of halo was observed. The diameter of the halo was recorded. The Enzymatic Index was then calculated by the following 
formula:

$$
\text { Enzymatic index }=\frac{\text { halodiameter }}{\text { colony diamter }}
$$

\subsection{Identification of Bacterial Isolates by Molecular Techniques}

Extraction of genomic DNA is accomplished by standard protocol of chloroform: isoamyl alcohol method.. Agarose gel electrophoresis was carried out for the visualization of isolated DNA. PCR was performed using the genomic DNA $(\sim 100 \mathrm{ng} / \mathrm{ml})$ as template and 16S r RNA specific primers. The sequence of $16 \mathrm{~S} r$ RNA gene was separated by PCR and automated sequencing.

\subsection{Germination Tests in Treated and Untreated Soil Samples}

In the present study, Pisum sativum (peas) was chosen for the seed germination test since it is a common fast growing leguminous plant available locally. Healthy, viable, uniformly sized seeds of peas were taken and then surface sterilized in $1 \% \mathrm{HgCl}$ for about 5 minutes followed by treatment in $100 \%$ alcohol for 3 minutes. The surface sterilized seeds were then sowed in trays which contained treated and untreated soil samples. After a few days of watering, the germination of the seeds was noted. The germination percentage can be calculated using the following formula:

$$
\text { Germination percentage }(\%)=\frac{\text { Number of seeds germinated } \times 100}{\text { Total number of seeds }}
$$

\section{Results and Discussion}

\begin{tabular}{|c|c|c|c|c|c|}
\hline Strain characteristics & Isolate 1 & Isolate 2 & Isolate 3 & Isolate 4 & Isolate 5 \\
\hline \multicolumn{6}{|l|}{ Morphological features } \\
\hline Colony color & White & White & White & white & White \\
\hline Cell shape & Rod & Rod & Rod & round & Rod \\
\hline Colony form & Circular & circular & Circular & irregular & Circular \\
\hline \multicolumn{6}{|c|}{ Physiological characteristics } \\
\hline Gram staining & Positive & positive & Positive & positive & Positive \\
\hline Capsule staining & Positive & positive & Positive & positive & Positive \\
\hline \multicolumn{6}{|c|}{ Biochemical characteristics } \\
\hline Indole & Negative & negative & Negative & negative & Negative \\
\hline Methyl red & Positive & negative & Positive & positive & Negative \\
\hline VP & Positive & negative & Positive & negative & Negative \\
\hline Citrate & Negative & positive & Positive & positive & Positive \\
\hline Urease & Positive & positive & Positive & positive & Positive \\
\hline catalase & Positive & positive & Positive & positive & Negative \\
\hline oxidase & Negative & positive & Positive & Positive & Negative \\
\hline glucose & Positive & positive & Positive & negative & Positive \\
\hline lactose & Negative & negative & Negative & negative & Negative \\
\hline sucrose & Positive & negative & Positive & negative & Positive \\
\hline maltose & Positive & negative & Positive & negative & Negative \\
\hline
\end{tabular}

Table 1. Staining and biochemical activities of purified cultures.

Table 2. Width of oil degradation by microbial isolates.

\begin{tabular}{lll}
\hline Isolates & Width of oil on zeroth day $(\mathbf{m m})$ & ${\text { Width of oil on } 7^{\text {th }} \text { day }(\mathbf{m m})}$ \\
\hline IS 1 & 6 & 0.9 \\
IS 2 & 6 & 1.0 \\
IS 3 & 6 & 1.0 \\
IS 4 & 6 & 1.4 \\
IS 5 & 6 & 1.2 \\
\hline
\end{tabular}

Table 3. Antibiotic sensitivity test.

\begin{tabular}{lll}
\hline Isolates & Ampicillin (zone of clearance) $\mathbf{m m}$ & Tetracycline (zone of clearance) mm \\
\hline IS 1 & 14 & 14 \\
IS 2 & 12 & 13 \\
IS 3 & 27 & 17 \\
IS 4 & 13 & 12 \\
IS 5 & 20 & 14 \\
\hline
\end{tabular}


Table 4. Evaluation of biosurfactant activity by drop collapse method and oil spread method.

\begin{tabular}{lll}
\hline Isolates & Biosurfactant activity by drop collapse method & Biosurfactant activity by oil spread method \\
\hline IS 1 & + & + \\
IS 2 & ++ & +++ \\
IS 3 & + & ++ \\
IS 4 & + & ++ \\
IS 5 & + & + \\
\hline
\end{tabular}

Table 5. Emulsification index $\left(E_{24}\right)$ of different isolates.

\begin{tabular}{llll}
\hline Isolates & Height of solution (H1) & Height of emulsion (H2) & Emulsification index (E A \%) \\
\hline IS 1 & 3.1 & 0.3 & $96.7 \%$ \\
IS 2 & 2.9 & 0.24 & $82.7 \%$ \\
IS 3 & 3.0 & 0.20 & $66.67 \%$ \\
IS 4 & 2.9 & 0.19 & $75.8 \%$ \\
IS 5 & 2.9 & 0.17 & $73.5 \%$ \\
\hline
\end{tabular}

Table 6. Qualitative analysis of enzyme activity.

\begin{tabular}{lll}
\hline Isolates & lipase enzyme zone of clearance & esterase enzyme zone of clearance \\
\hline IS 1 & $18 \mathrm{~mm}$ & $20 \mathrm{~mm}$ \\
IS 2 & $19 \mathrm{~mm}$ & $14 \mathrm{~mm}$ \\
\hline
\end{tabular}

Identification of the genome of unknown bacteria.

The five isolates were identified based on the genome sequencing and using BLAST.

The organism was identified as Bacillus subtilis, Pseudomonas aerogenosa, pseudomonas aerugenosa, Micrococcus flavus, Bacillusamyloliquefaciens respectively

Table 7. Effect of treated and untreated soil samples in the germination of Pisum sativum.

\begin{tabular}{ll}
\hline Sample & Germination percentage \\
\hline Untreated soil & $25 \%$ \\
Treated soil & $75 \%$ \\
\hline
\end{tabular}

The soil site with the best biosurfactant activity was chosen for the germination study. The present investigation led to the preliminary assessment and comparison of the biosurfactant effect in treated and untreated samples by germination test. After a period of time the germination percentage was calculated. The germination percentage in the treated soil $(75 \%)$, was clearly greater than that of the untreated soil. To conclude, the results confirmed that the bioremediation mediated sample has been very effective

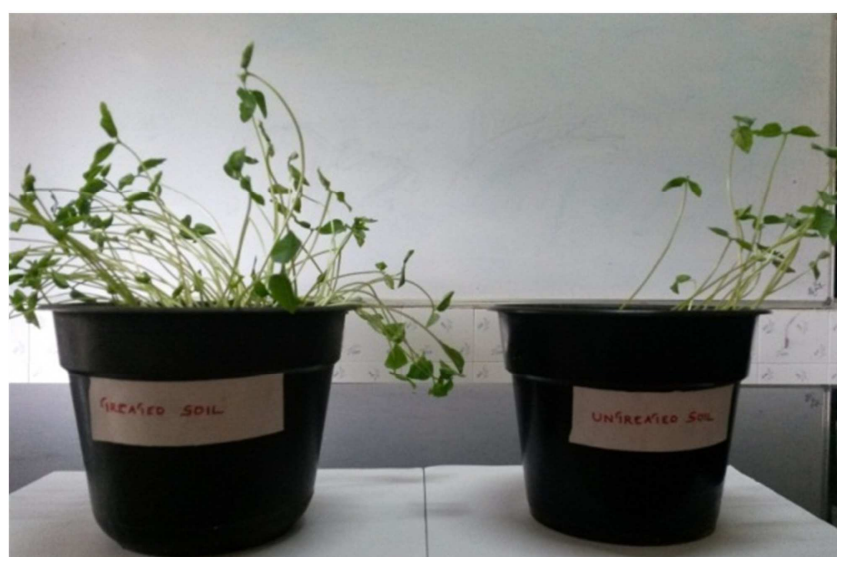

Figure 1. Germination test of psium sativum.

\section{Conclusion}

Humans have often been involved in activities which have led to the destruction of the environment. Industrialization has led to a tremendous increase in the accumulation of waste products and causes damage to the environment. Oil pollution is one of the worst types of pollution. Wastes emanating from industries and oil refineries, which contain petroleum hydrocarbons, metals, radioactive materials and salts, have the potential to cause soil pollution preventing the growth of plants. The conventional techniques of remediation have some majordisadvantages. The recent trend in environmental remediation is by the use of 'Bioremediation' by 'Biostimultion'. Since bioremediation is based on the process of natural attenuation it is considered to be more acceptable than other technologies. The present study has shown that the indigenous Bacillus $s p$., isolated from the polluted study sample (Kochi) possessed the capacity to produce suitable biosurfactant. The biosurfactant isolated from the bacteria showed increased lipase and esterase enzyme activity. Therefore it was used for the degradation of oil contaminated soil. The fertility and toxicity of the soil before and after the treatment was assessed. The effectiveness of the bioremediation mediated by the biosurfactant extract was studied by finding out the germination percentage of a fast growing leguminous plant (Pisum sativum). It was observed that the germination percentage in the treated soil was notably greater. Therefore the findings of the study revealed that the bacillus $s p$., isolated from Kochi possesses remarkable oil degrading properties and can be effectively employed in the bioremediation of oil contaminated soils. The results also prove that biostimulation is an effective method of reducing environmental pollution. It can be considered as one the effective clean-up technologies of the future. By implementing this method, pollution can be effectively mitigated and the balance in the ecosystem can be restored. 


\section{References}

[1] Aneja K R, Experiments in microbiology, plant pathology and biotechnology, New AgeI nternational (p). Ltd, Publishers, New Delhi, 2003, Fourth edition.

[2] Atlas, R. M. 1995. Bioremediation of petroleum pollutants. International Biodeterioration and Biodegradation 35: 317327.

[3] Baker J. M., Mangroove swamps and the oil Industry, Environ. Pollut. Bull., 12 (1982).

[4] Barathi S, Vasudevan N, Utilization of petroleum hydrocarbons by Pseudomonas fluorescensisolated from petroleum contaminated soil, 2001, 26: 413-416.

[5] Emad I Hussein, Fuad A Al Horani and Hanam I Malkawi Year: 2012 | Volume: 11 | Issue: 4 | Page No.: 189-198.

[6] Godleads Omokhagbor Adams Prekeyi Tawari Fufeyin, Samson Eruke Okoro, Igelenyah Ehinomen International Journal of Environmental Bioremediation \& Biodegradation, 20153 (1), pp 28-39.

[7] Ian M. Head, D. Martin Jones \& Wilfred F. M. Röling, Nature Reviews Microbiology 4, 173-182 (March 2006).

[8] Jahir Alam Khan and Syed Hasan Abbas Rizvi. Isolation and characterization of micro-organism from oil contaminated sites Adv. Appl. Sci. Res., 2011, 2 (3): pp. 455-460.

[9] Jayashree, R., Evany Nithya, S., Rajesh Prasanna, P and Krishnaraju, M. (2012). Biodegradation capability of bacterial species isolated from oil contaminated soil. J. Acad. Indus. Res., 1 (3), pp. 140-143.

[10] Kumar, B. R., Maheswaran, R., Kartheek, G and Sharmila banu, G. 2011. Biodegradation of Cyclohexanol by Microorganisms Isolated From Oil Spilled Soil around Namakkal. International Journal of Pharmaceutical \& Biological Archives. 2 (5): pp. 1426-1429.

[11] K Watanabe - Current opinion in biotechnology, 2001 Elsevier Volume 12, Issue 3, 1 June 2001, Pages 237-241.

[12] Laws, E. A. 1993. Aquatic pollution: An introductory text. John Wiley and Sons, New York, New York, USA.

[13] Margesin, R., and F. Schinner. 1997a. Laboratory bioremediation experiments with soil from a diesel-oil contaminated site: Significant role of cold-adapted microorganisms and fertilizers. Journal of Chemical Technology and Biotechnology 70: 92-98.

[14] Marquez-Rocha, F. J., Hernandez-Rodriguez, V., Lamela, M. T., (2001), Biodegradation of diesel oil in soil by a microbial consortium. Water Air Soil Pollut. 128, pp. 313-320.

[15] Moorthi SP, Deeccaran M and Kalaichelvan TP, 2008, Advanced Biotechnol, 34-36.

[16] Ortega CJJ, Marchenko AJ, Vorobyov AV, Borovick RV, FEMS. Microbiol. Ecol, 2003, 44: 373-381.

[17] P. K. Jain, V. K. Gupta, R. K. Gaur, M. Lowry, D. P. Jaroli and U. K. Chauhan, 2011. Bioremediation of Petroleum oil Contaminated Soil and Water. Research Journal of Environmental Toxicology, 5: 1-26.

[18] Rodrigues, L. R., J. A. Teixeira, H. C. Mei and R. 2006. Oliveira Physicochemical and Functional Characterization of a Biosurfactant Produced by Lactococcus lactis 53, Colloids and Surfaces B: Biointerfaces., 49: pp. 79-86.

[19] Singh C, Lin J, African J. Biotechnol, 2008, 7 (12): 1927-1932. 